\section{Estandarización fotográfica en Cirugía Plástica y Estética}

\section{Photographic standardization in Plastic and Aesthetic Surgery}

Solesio Pilarte, F.*, Lorda Barraguer, E.**, Lorda Barraguer, A.***, Laredo Ortiz, C.*, Rubio Verdú, R. ${ }^{* * * * *}$

\section{Resumen}

Una de las herramientas más útiles con las que cuenta el cirujano plástico y estético de hoy en día es la fotografía. Cirugía Estética y fotografía son inseparables. El registro fotográfico de pacientes para crear un archivo permanente es esencial para especialidades como la nuestra por varios motivos: ayudar al diagnóstico, facilitar la relación médico-paciente, dejar constancia documental, para protección legal y como herramienta de marketing, entre otros. Por consiguiente son importantes la estandarización y las recomendaciones referentes a fotografía clínica, que deben ser bien conocidas por los profesionales. A pesar de que son numerosos los artículos referentes a esta materia, todavía es frecuente encontrar en publicaciones y presentaciones en congresos imágenes que no satisfacen unos estándares mínimos de calidad fotográfica. Es importante que nuestro archivo fotográfico sea consistente, comparable y esté bien organizado para que pueda ser usado fácilmente y con eficacia.

\author{
Palabras clave Fotografía, Cirugía Plástica, Cirugía \\ Estética, Estandarización \\ Código numérico 14-143
}

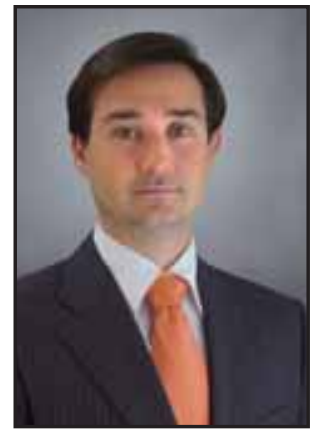

Solesio Pilarte, F.

\section{Abstract}

Photography is one of the most useful tools today plastic surgeons rely on. Aesthetic Surgery and photography are inseparable. To build up a permanent archive, patients' photographic records are essential in specialities such as Aesthetic Surgery for several reasons: help in diagnosis, ease patient-doctor relationship, leave documentary record, legal protection and marketing tool among others. For these reasons standardization and clinical photography recommendations are important and should be well known by professionals. Published articles about this topic are numerous, however is common to find photographs in medical publications and congresses in which minimal photographic standards are not reached. Having a consistent, comparable and well organized photographs archive is important in order to be used easily and efficiently.

$\begin{array}{ll}\text { Key words } & \begin{array}{l}\text { Photography, Plastic Surgery, Aesthetic } \\ \text { Surgery, Standardization }\end{array} \\ \text { Numeral Code } & 14-143\end{array}$




\section{Introducción}

En las últimas décadas, la documentación gráfica de nuestros pacientes en la práctica diaria ha incrementado su importancia. En la actualidad, la cámara fotográfica (digital habitualmente), ha pasado a formar parte del bagaje que portamos en nuestros maletines los cirujanos plásticos y estéticos. A diario acontecen situaciones para realizar fotografías, no sólo en la consulta, sino también en el antequirófano o en el campo quirúrgico. Las fotografías nos permiten planificar cirugías, explicar detalles de las mismas o del resultado al propio paciente, evaluar resultados, realizar docencia, protegernos legalmente, atestiguar lesiones para las compañías de seguros y, cómo no, compartir información con otros colegas.

El uso de la fotografía en nuestra especialidad comenzó aproximadamente hace unos 150 años. Ya Rogers (1) mencionó en su artículo que Gurdon Buck (1807-1877) fue el primer cirujano en la historia en publicar, en 1845, un artículo con ilustraciones preoperatorias de un paciente. Unos años después, en 1852, Berhrend (un traumatólogo de Berlín), empleó imágenes pre y postoperatorias de un paciente (2). Un profesor de Cirugía de la Universidad de Budapest, James Balossa, fue quien en el año 1863 escribió un libro en el que describía una reconstrucción nasal en dos tiempos empleando para ello 7 fotografías (2) y que, al parecer, fue el primer registro fotográfico de un procedimiento reconstructivo.

En los años siguientes, el uso de cámaras fotográficas fue convirtiéndose en algo cada vez más asequible y su uso se fue popularizando. Los avances tecnológicos consiguieron la portabilidad de la cámara hasta límites que antes eran inimaginables, como con los actuales teléfonos-cámara.

Como dijo Sir Harold Gillies durante el primer congreso internacional de Cirugía Plástica en Estocolmo, "la fotografía ha sido uno de los avances más importantes en Cirugía Plástica” (3).

Pero la utilidad de la fotografía en nuestra especialidad alcanza su máximo nivel cuando está realizada en condiciones estándar. Diferentes variables influyen en el resultado final de las fotografías de nuestros pacientes, tales como la distancia paciente - cámara, la iluminación, la exposición, etc., que pueden dar falsas impresiones, por lo que es fundamental que todos sean reproducibles y controlados para eliminar confusiones.

A pesar de existir publicaciones acerca de esta materia, aún se siguen viendo muy a menudo en publicaciones y congresos imágenes que no cumplen los estándares de fotografía en Cirugía Plástica y Estética. Por ello hemos decidido revisar los artículos publicados al respecto y recopilar una lista de recomendaciones para la estandarización de la fotografía en nuestra especialidad.

\section{Material y método}

Para poder tomar fotografías clínicas necesitaremos los siguientes elementos: cámara, iluminación, fondo y ubicación. Además tendremos en cuenta aspectos tales como la posición del paciente, distancia, ángulos de disparo y punto de enfoque.

\section{Cámara}

Aunque es cierto que lo ideal sería emplear una cámara con objetivos intercambiables para poder emplear el más apropiado en cada situación, debemos tener en cuenta que realizar continuamente dichos cambios no resulta cómodo y mucho menos transportar tanto material de un lado a otro (consulta, quirófano, etc.). Por consiguiente, debemos encontrar un equilibrio entre la calidad fotográfica y la sencillez técnica para así poder tener unos buenos resultados sin convertir el proceso fotográfico en algo engorroso; tendremos que sacrificar calidad fotográfica en aras de la comodidad para poder tener resultados reproducibles con sencillez. Actualmente disponemos en el mercado de cámaras analógicas y digitales; ambos tipos pueden tener o no objetivos intercambiables.

En este artículo, haremos referencia exclusivamente al empleo de cámaras digitales dada su popularidad en la actualidad, su sencillez de uso y tener una ventaja enorme frente a las de película tradicionales: el poder apreciar el resultado de la imagen al instante. Las cámaras digitales compactas resultan una alternativa más cómoda que las de objetivos intercambiables debido a su ligero peso y a su pequeño tamaño. También son más fáciles de manejar, aunque la calidad óptica ofrecida sigue siendo inferior. A pesar de que la tecnología avanza rápidamente y la calidad de las compactas ha mejorado extraordinariamente, desde nuestro punto de vista es recomendable el uso de cámaras digitales reflex ya que ofrecen una calidad óptica superior y permiten mayor control de los parámetros fotográficos.

Se recomienda emplear siempre la misma cámara ya que modelos distintos de cámaras fotográficas digitales manejan con distinta efectividad el balance de blancos, la saturación del color y otras características de las que depende el resultado de la imagen. La coloración de la piel (y de las cicatrices), depende del balance de blancos, por ello se recomienda usar una cámara que permita su control y debemos saber cómo manejarlo correctamente. 


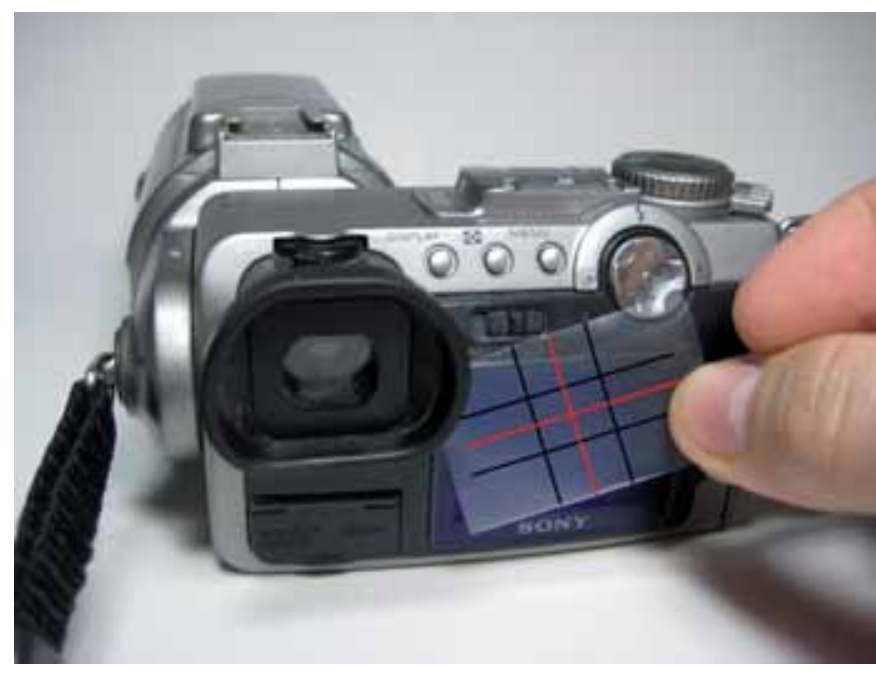

Fig. 1. Rejilla añadida a la cámara.

Entre las múltiples posibilidades que se ofertan en el mercado, aconsejamos algunas características mínimas:

-- Resolución (cantidad de puntos que componen la imagen) de al menos 8 megapixeles si queremos hacer ampliaciones.

-- Zoom de al menos 3 aumentos ópticos (3X) (no confundir con el zoom digital que es simplemente un recorte ampliado de la imagen).

-- La pantalla LCD debe tener un tamaño suficiente para poder ver bien el resultado de la fotografía (habitualmente más de 2,5 pulgadas), si bien siempre podremos recurrir a la ampliación de la imagen para ver mejor los detalles de las fotos.

.- Tamaño del sensor CCD (el equivalente a la película de las cámaras analógicas), pues a mayor tamaño, mayor calidad de imagen (es mayor en las reflex que en las compactas).

-- Debe tener la función macro de enfoque.

Algunos modelos permiten el uso de líneas-guía en la pantalla que ayudan a encuadrar mejor el motivo de la foto y a evidenciar las asimetrías. Para los modelos que no las tengan, una manera económica y fácil de lograr el mismo fin es pintar una cuadrícula sobre una lámina transparente de acetato o similar y adherirla a la pantalla de la cámara (también se comercializan) (Fig. 1, 2). La cuadrícula nos sirve para comprobar que el paciente está colocado correctamente respecto a la referencia horizontal/vertical, que su posición es correcta (por ejemplo que los hombros están a la misma altura) y que el punto central de la imagen corresponde con el que queremos. Este es el primer paso para encontrar consistencia y reproducibilidad en nuestras fotografías

\section{Iluminación}

Se recomienda emplear dos fuentes principales de iluminación difusa (flashes de ventana) (Fig. 4) que

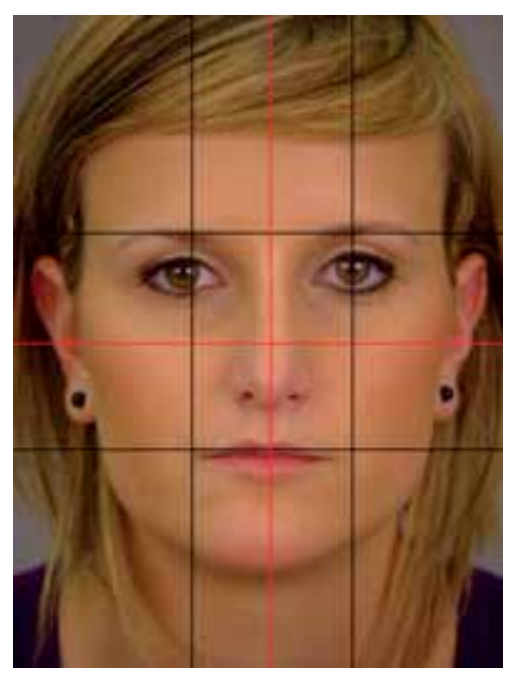

Fig. 2. La rejilla sirve para encuadrar correctamente.

incidan en el motivo fotográfico (paciente) a 45 grados cada una (4) y estén situadas a la misma altura (aproximadamente a la misma altura que la cámara). A pesar de ello, se producirán dos sombras en el fondo de la imagen que pueden llevar a engaño. Por ello conviene suplementar la iluminación del fondo con otras dos luces menores situadas a los lados o por detrás del paciente y a un metro de distancia del fondo (Fig. 3). Este esquema de iluminación eliminará las sombras, pero con ello se aplanará la imagen. Si queremos apreciar el relieve en la imagen (acné, lipomas, arrugas, etc), precisaremos de otros ángulos de iluminación. Todas estas luces pueden estar encendidas durante la sesión fotográfica o encenderse sincrónicamente con nuestro disparo. Para ello existen en el mercado dispositivos cableados o, lo que es más cómodo, flashes esclavos inalámbricos.

Para la fotografía facial, una alternativa más sencilla y económica a este montaje es la propuesta por Meneghini (5), que emplea un raíl en el techo por el que desplaza un flash que se puede posicionar a dis-

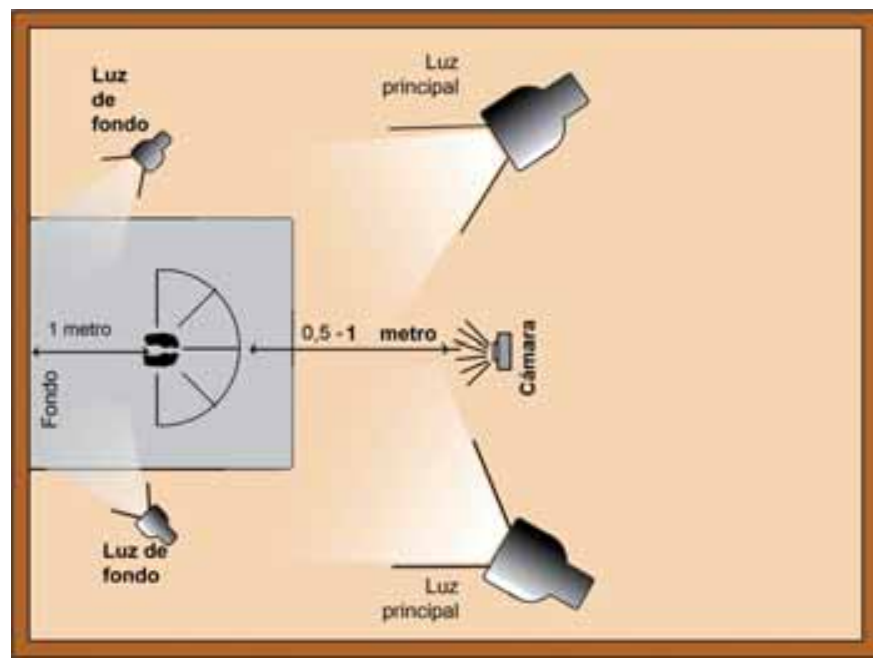

Fig. 3. Plano del estudio fotográfico. 


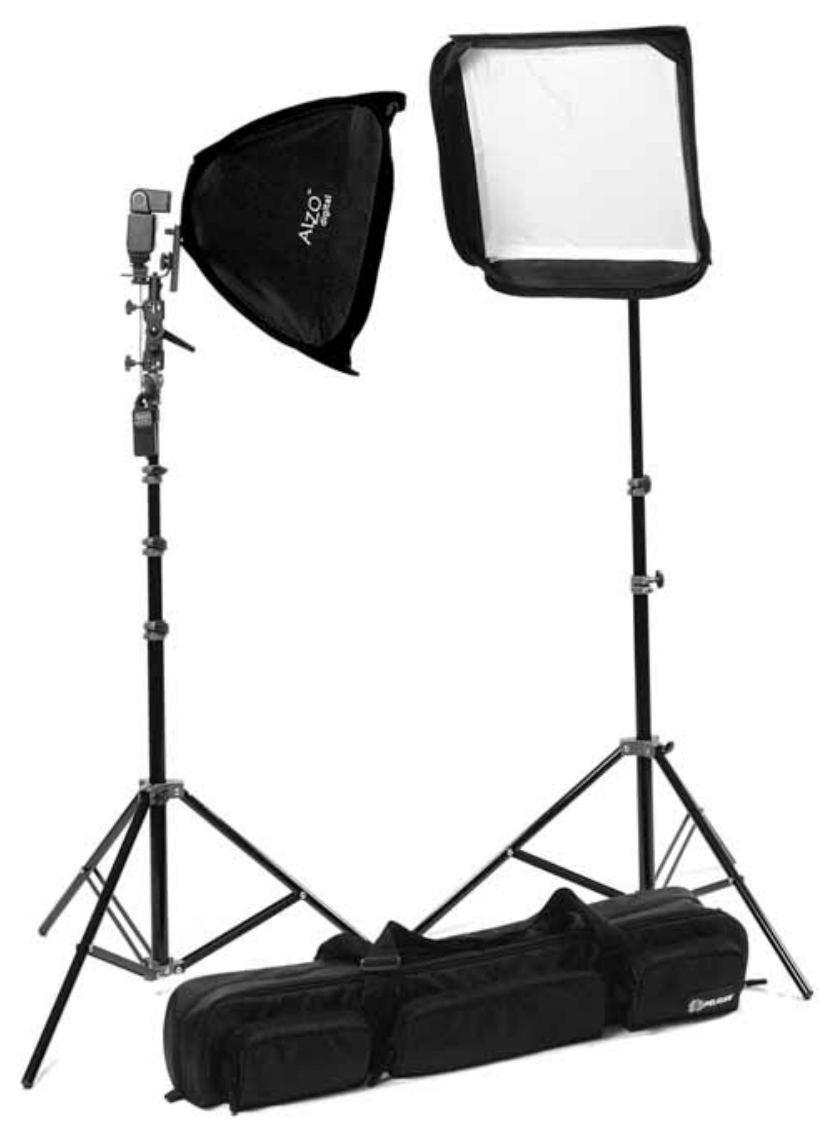

Fig. 4. lluminación difusa.

tintas alturas gracias a un pantógrafo que une el flash al raíl. Ayudado por un panel reflectante, elimina las sombras del mentón.

En caso de no disponer de la iluminación auxiliar mencionada, es al menos recomendable el empleo de un flash independiente del cuerpo de la cámara con difusor y, a ser posible, sincronizado por control remoto. Teniendo en cuenta que operamos a distancias no muy grandes, no necesitamos mucha potencia. Si sólo disponemos de un flash y está unido al cuerpo de la cámara, siempre podremos girar la cámara colocado el flash en la posición mas conveniente con respecto al objetivo para ocultar las sombras. Por ejemplo, si queremos esconder las sombras al fotografiar la cara desde el lado izquierdo del paciente, deberemos colocar el flash a la izquierda del objetivo girando la cámara 90 grados en sentido antihorario (Fig. 5 centro).

En el caso de fotografía en cavidades (boca, úlceras, etc.) la sombra que proyecta la pared de dicha cavidad puede dificultar la observación del fondo. Por ello, en estas situaciones, recomendamos emplear flashes anulares que eliminan las sombras. Una característica de dichos dispositivos es que aplanan la imagen. Para evitarlo, existen en el mercado algunos modelos que permiten controlar por separado la intensidad de la luz de las distintas zonas del anillo (Fig. 6 y 7).

\section{Fondo}

El fondo es otro de los elementos fundamentales a la hora de realizar fotografías clínicas. Es importante que no distraiga la atención del motivo principal de la fotografía y para ello debe ser uniforme (Fig. 8). Al realizar el disparo puede pasarnos inadvertido que se vean otros objetos como las baldosas del suelo, la mano del anestesista, la manilla de una puerta, etc. Estas imágenes son inaceptables en cursos, congresos o publicaciones.

Las cámaras digitales ajustan automáticamente la cantidad de luz recibida de la imagen variando la exposición. Por esto, si fotografiamos a un paciente de piel clara delante de un fondo muy oscuro, la cámara aumentará la sensibilidad de la foto haciendo que la piel se vea incluso más clara de lo que es (Fig. 9). Por el contrario, al fotografiar sobre fondo blanco, saldrá más oscura en la fotografía. Se considera que el fondo ideal debe ser azul claro $(6,7)$ o gris medio (aquel que refleja el 18\% de la luz que llega, nivel considerado como neutro en la exposición fotográfica
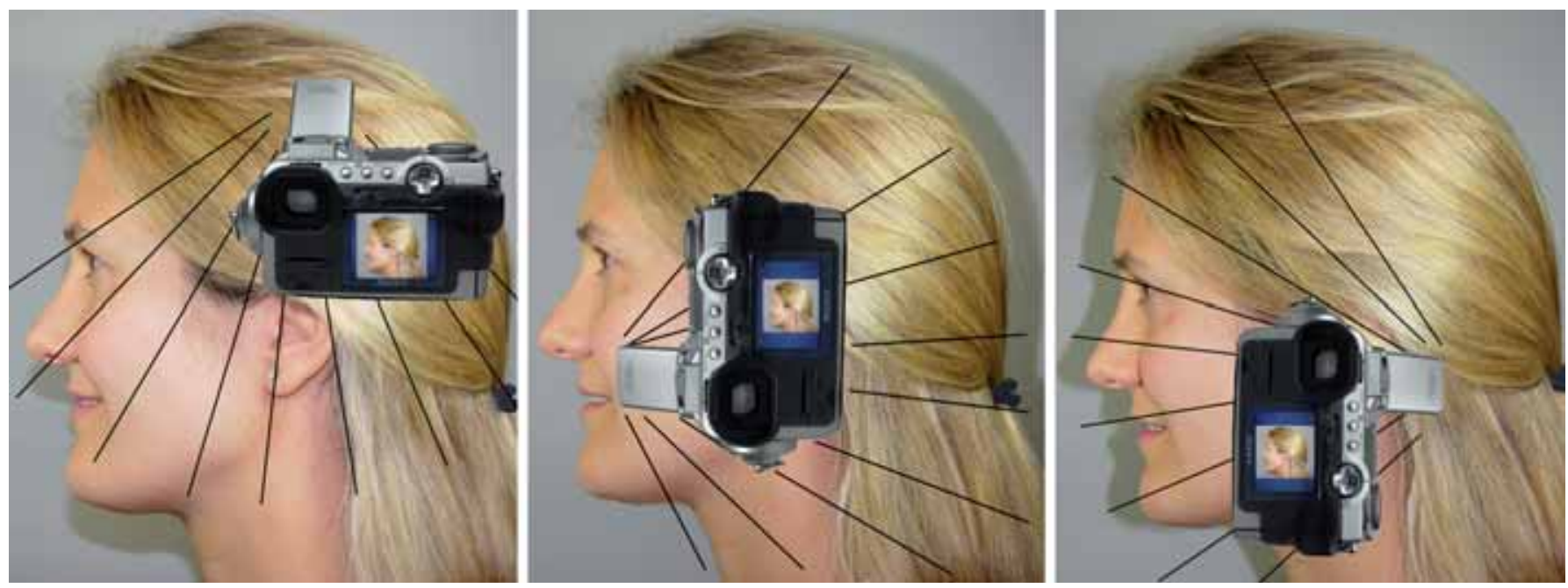

Fig. 5. Debemos orientar la cámara para evitar que la sombra del flash moleste. 


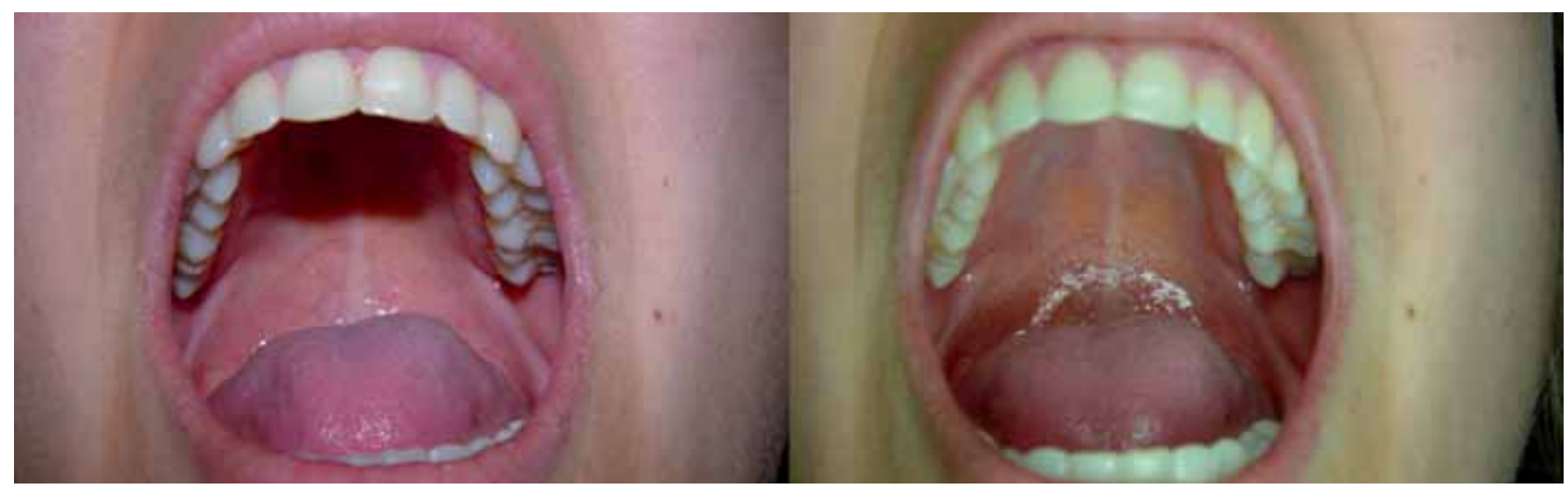

Fig. 6. El flash anular evita sombras en cavidades.

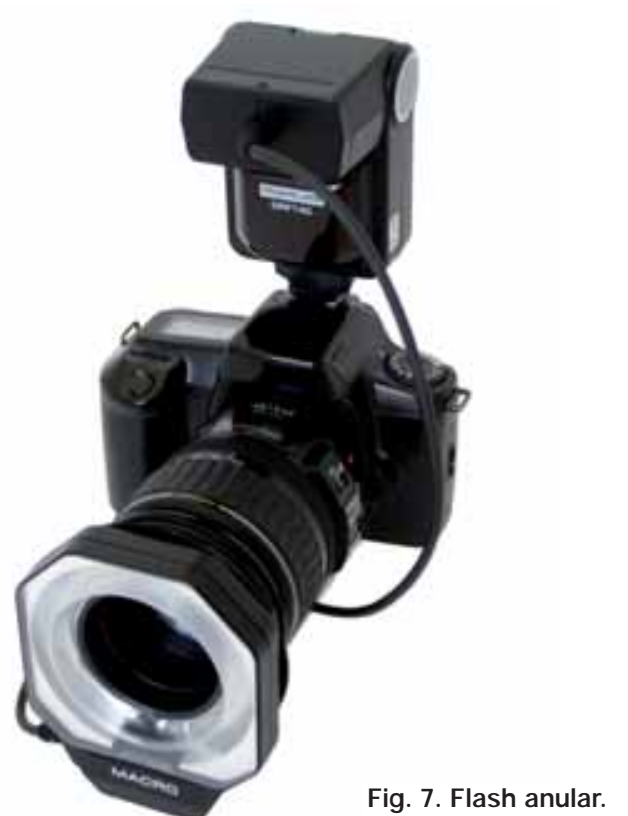

de interiores. De este modo el color de la piel se apreciará con más naturalidad. Desde nuestra experiencia, creemos recomendable que el fondo sea un estor enrollable cuya longitud exceda en unos $80 \mathrm{~cm}$. la distan- cia hasta el suelo, de modo que, al realizar fotografías de las piernas, el fondo se pueda estirar pasándolo por debajo de los pies del paciente, quedando una curvatura uniforme que disimule la unión entre el suelo y la pared y evite así la visión de elementos que distraigan la atención, como rodapiés, uniones de baldosas, pared, etc. Esta tela debe ser mate para obtener resultados óptimos.

\section{Ubicación y Posición del paciente}

El paciente debe situarse en un área cómoda dejando espacio entre él y la pared para poder así, desde ese espacio, iluminar el fondo y eliminar la sombra del paciente. La habitación debe asegurar la privacidad del paciente, especialmente si tenemos en cuenta que solemos fotografiar pacientes con áreas anatómicas íntimas expuestas. Una habitación dedicada a la fotografía de unos 12 $\mathrm{m}^{2}(2,5 \times 4,5 \mathrm{~m})$ es suficiente para este propósito (8) (Fig. 3). Es útil disponer de un taburete giratorio.

Es recomendable también que estemos asistidos por dianas o cuadros situados estratégicamente en aquellos puntos de las paredes hacia donde queramos que miren los pacientes (normalmente a 45 y a 90 gra-
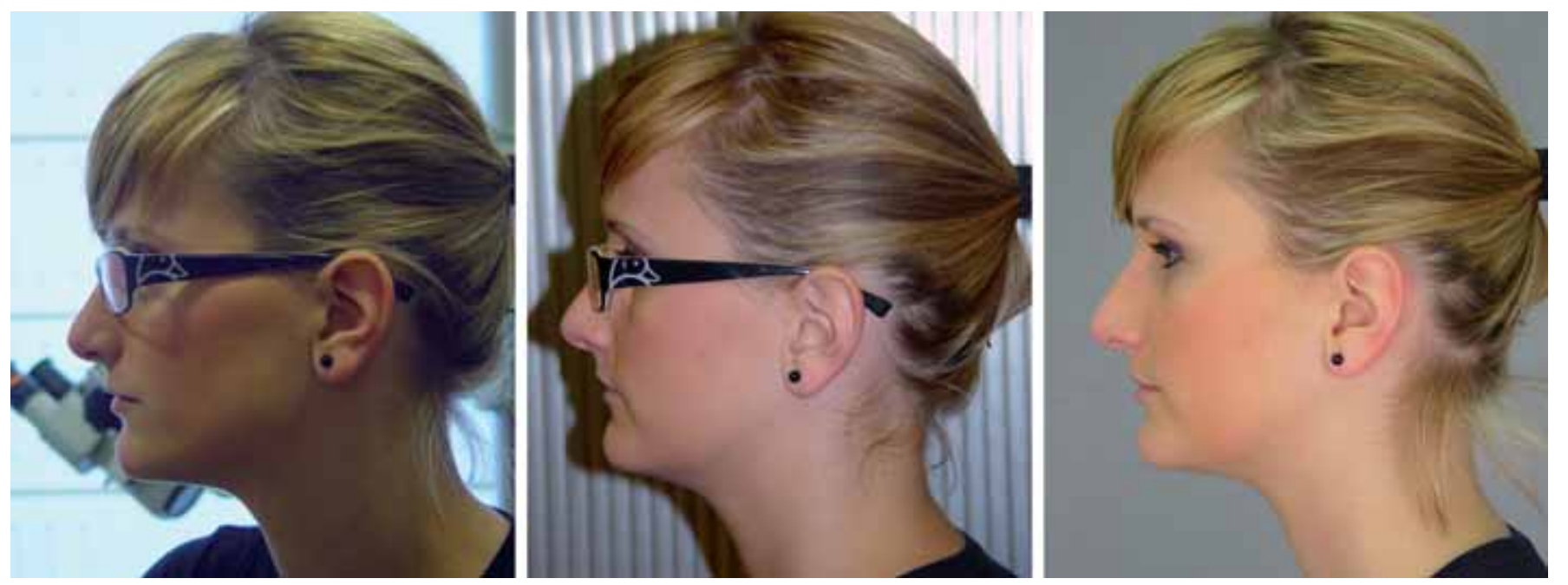

Fig. 8. Izquierda y centro: mala elección del fondo. Derecha: buena elección de fondo. 

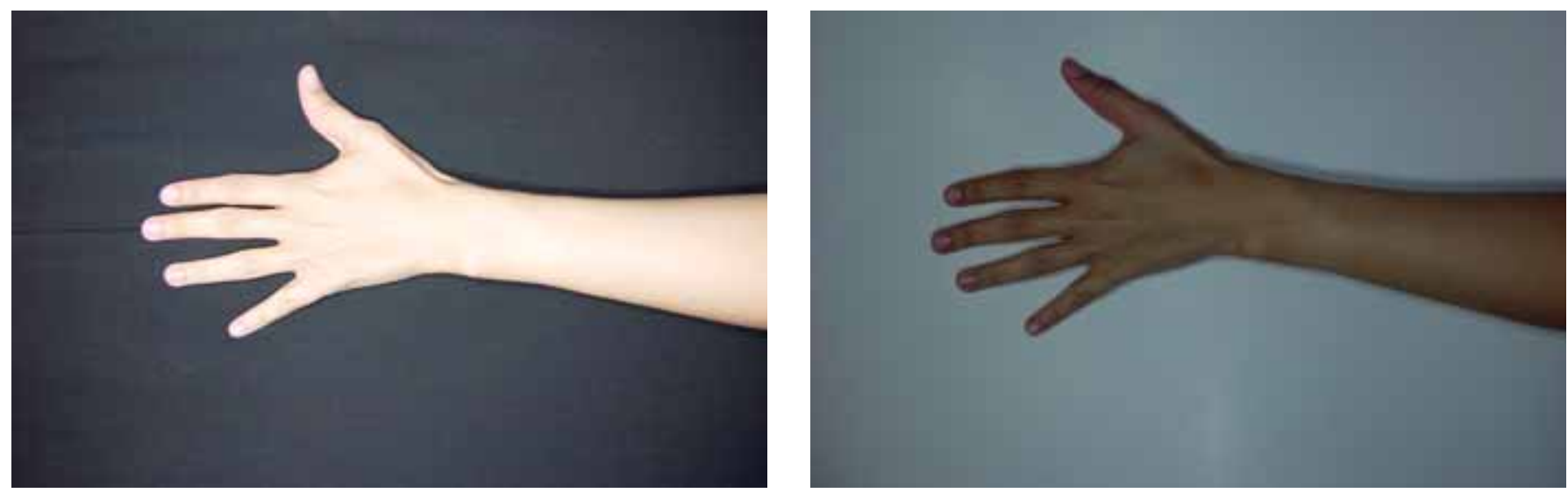

Fig. 9 (a y b). Los fondos claros hacen que la piel parezca más oscura. Los fondos oscuros la hacen parecer más clara.

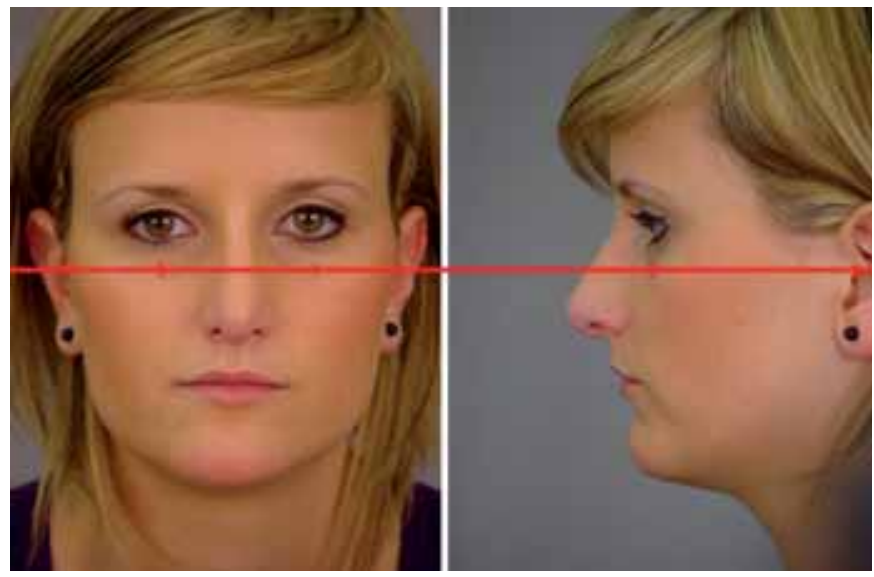

Fig. 10. Línea de Frankfort. Reborde orbitario inferior - conducto auditivo externo).

dos) (8). También puede ser útil el empleo de plantillas en el suelo, con dibujos marcando los mencionados ángulos.

En caso de fotografía facial lateral, una manera fácil y rápida de asegurar que estamos fotografiando una vista lateral reproducible es pedir al paciente que abra la boca al máximo y alinear nuestro objetivo con ambas comisuras bucales, para a continuación pedirle que cierre la boca sin mover la cabeza. En fotografía facial una referencia clara y fácil de emplear es la línea de Frankfort, que debe ser paralela a nuestra rejilla de encuadre (Fig. 10).

En el caso de querer fotografiar el tronco, los brazos deben separarse del abdomen para permitir apreciar correctamente la línea de su contorno. Además, la ropa debe ser retirada previa y completamente, no siendo válidas fotografías con la camisa desabrochada, por ejemplo. Para fotografiar las mamas en la vista de tres cuartos, habrá que colocar a la paciente con el brazo más lejano en discreta retroversión.

Asimismo, para la fotografía de las manos se debe remangar la camisa hasta conseguir que no aparezca vestimenta dentro del encuadre y, por supuesto, retirar relojes, pulseras y anillos.

\section{Distancia}

Según la distancia a la que efectuemos el disparo, la distorsión que sufre el modelo varía. En imágenes tomadas de cerca, las facciones más próximas a nosotros van a parecer mayores de lo que realmente son y las más distantes parecerán menores, creándose un efecto de "reflejo en bola de árbol de Navidad". Por ello es recomendable alejarnos del paciente y agrandar la imagen usando el zoom óptico, ya que se distorsionan menos las imágenes tomadas desde lejos y ampliadas con el zoom que las imágenes sin zoom, pero tomadas a "bocajarro". Una manera de repetir siempre la distancia empleada es haciendo que la parte fotografiada llene completamente la pantalla de encuadre o se ajuste a la rejilla de encuadre, como veremos más adelante. También puede resultar de gran ayuda el uso de una pequeña marca adhesiva en el suelo para recordar la distancia. Se aconseja establecer un grado de zoom constante según las dimensiones de la consulta y las características de la cámara. Otra situación distinta se plantea cuando queremos
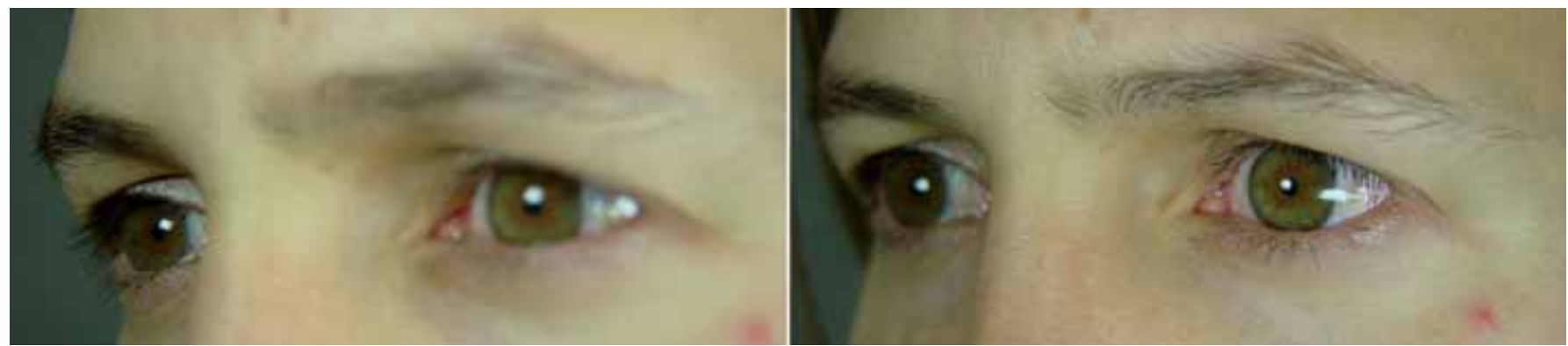

Fig. 11. Es importante enfocar el punto deseado (Izq.: ojo derecho enfocado). (Dcha: ojo izquierdo enfocado). 


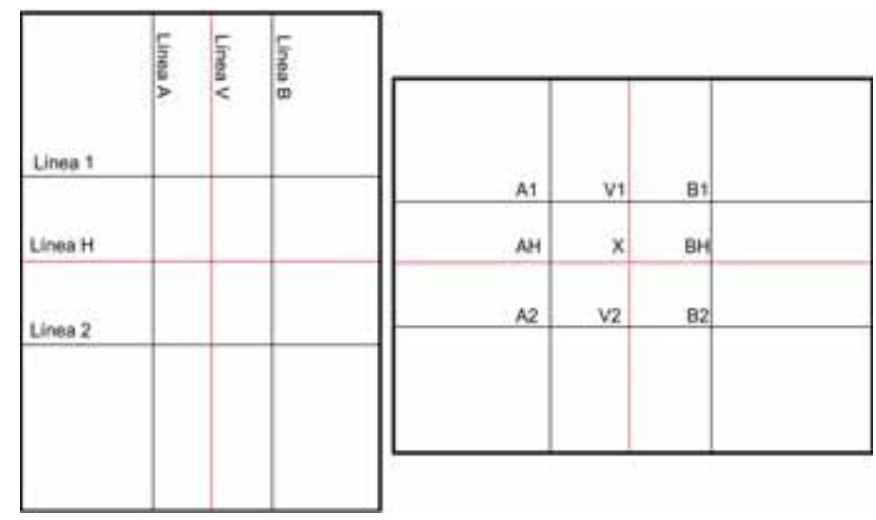

Fig. 12. Nomenclatura de puntos de referencia.

fotografiar un detalle, como por ejemplo un nevus o una cicatriz. En estos casos debemos emplear el macro de enfoque y reducir el zoom al máximo, siendo siempre más recomendable ampliar la foto a base de acercar la cámara que usando el zoom. De esta manera conseguiremos un enfoque mejor.

\section{Punto de enfoque}

Es importante asegurarnos de que estamos enfocando correctamente aquello que queremos fotografiar. La mayoría de las cámaras digitales de hoy en día poseen un dispositivo para saber qué parte de la imagen se está enfocando (control de enfoque); esto es especialmente útil cuando estamos realizando fotografías en modo macro, donde la profundidad de campo está muy disminuida y por tanto sólo aparecerán enfocados los puntos situados en un rango muy estrecho de distancias a nuestro objetivo (Fig. 11). Si nuestro equipo dispone de control de enfoque, debemos configurarlo a la posición de enfoque manual (en el centro de la imagen); de este modo, al hacer por ejemplo fotografías intraorales, nos enfocará el paladar y no los dientes.

\section{Otros aspectos}

El paciente debe retirarse los artículos de joyería que lleve puestos en la zona a fotografiar. Asimismo el pelo debe estar recogido si vamos a fotografiar detalles de la cara. El maquillaje es aceptable si no es excesivo, salvo en aquellos casos en los que se planee realizar un procedimiento cutáneo como dermoabrasión, láser o peeling químico (4).

Los pacientes deben ser avisados del propósito de la fotografía y deben firmar, previamente, una autorización conforme a ello. Asimismo, en España es de obligado cumplimiento la ley de protección de datos de carácter personal, la cual incluye todo lo relativo a la fotografía con fines clínicos.

\section{Parámetros propuestos para áreas anatómicas específicas}

Denominaremos $\mathrm{H}$ y $\mathrm{V}$ a las líneas medias horizontal y vertical respectivamente, A y B a las líneas verticales de separación de tercios, y 1 y 2 a las horizontales tal y como se muestra en la Figura 12.

Se establecen por tanto 9 puntos de intersección nombrados según las líneas que los definen. Al punto central lo denominaremos $\mathrm{X}$.

a) Cara completa (Fig. 13)

- Posiciones del paciente: Bipedestación, en posición anatómica, mirando al horizonte con vistas frontal, 3/4 derecha, lateral derecha, 3/4 izquierda y lateral izquierda. En las vistas laterales alinearemos las comisuras de la boca. En las oblicuas, el nasion estará alineado con el canto medial del ojo más lejano.

- Orientación de la cámara: Vertical

- Altura de la cámara: En la línea horizontal de Frankfort del paciente.

- Distancia: A 1 metro del paciente.

- Zoom: El necesario para que las líneas 1 y 2 coincidan con las cejas y la boca respectivamente (aproximadamente X3).

- Límites de encuadre: Desde cuello hasta cuero cabelludo.

- Punto de enfoque: Pestañas del ojo más cercano.
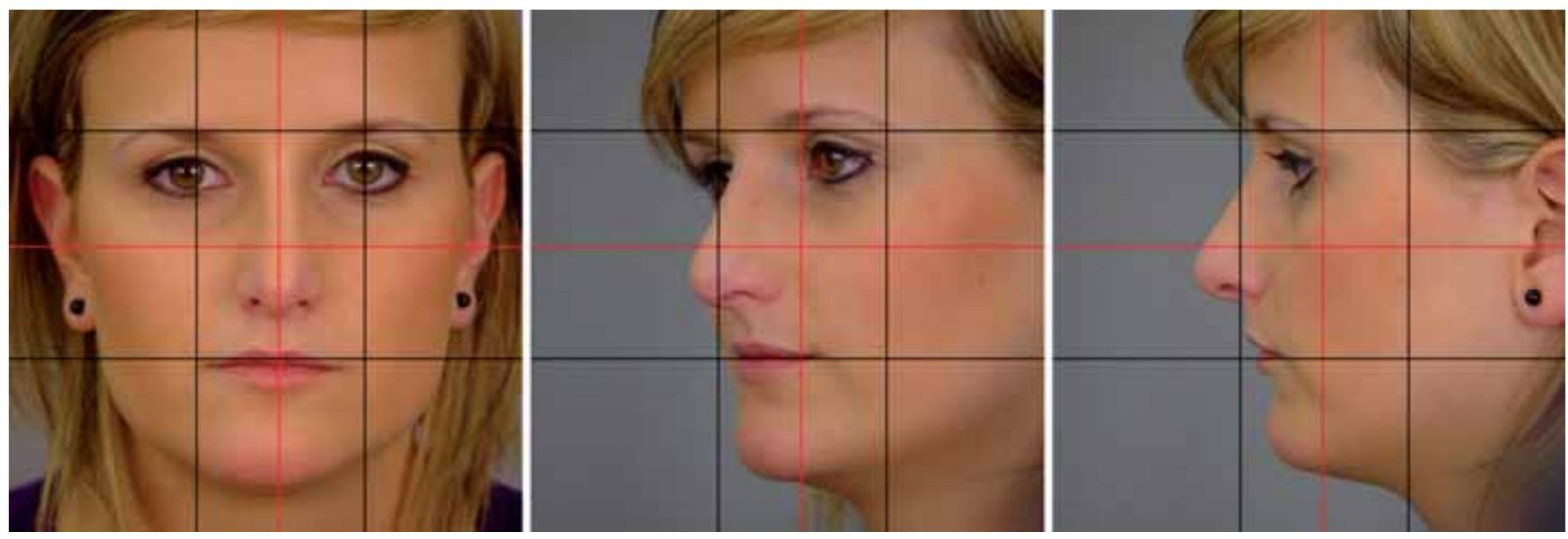

Fig. 13. Vistas faciales. 


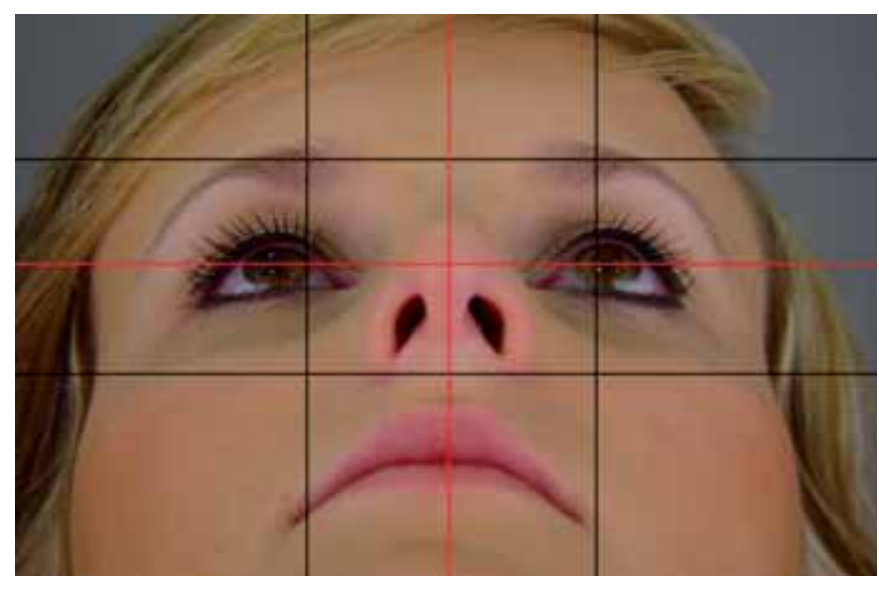

Fig. 14. Vista basal de la nariz.

- Velocidad: Por lo menos 1/125. Si es menor, deberemos usar trípode.

- Apertura: La suficiente para alcanzar velocidades de $1 / 125$ o ligeramente superiores.

- Puntos de referencia: Línea 1 sobre las cejas. Línea 2 sobre boca.

- Frontal - Línea media sagital sobre línea V.

- Oblicuas - Línea V pasando por canto interno del ojo más cercano.

- Lateral - Línea V pasando por canto externo.

\section{b) Vista basal de la nariz (Fig. 14)}

- Posición del paciente: Bipedestación, con la barbilla levantada hasta alinear la punta nasal con los párpados superiores.

- Posición de la cámara: Horizontal.

- Altura de la cámara: A la misma de los ojos del paciente.

- Distancia: 0,5 metros.

- Zoom: El necesario para conseguir los puntos de referencia propuestos.

- Límites de encuadre: Incluir labio superior hasta trichion en vertical y ambas sienes en horizontal.

- Punto de enfoque: Alas nasales
- Velocidad: Por lo menos 1/125. Si es menor, deberemos usar trípode.

- Apertura. La suficiente para alcanzar velocidades de 1/125 o ligeramente superiores.

- Puntos de referencia

- Línea H a la altura de las pupilas.

- Línea V, la línea media del paciente.

- Línea 1 a la altura de las cejas

c) Ojos (Fig. 15)

- Posiciones del paciente: Bipedestación, en posición anatómica, mirando al horizonte con vistas frontal, frontal cerrando los ojos y frontal mirando hacia arriba 3/4 derecha, lateral derecha, 3/4 izquierda y lateral izquierda.

- Orientación de la cámara: Horizontal.

- Altura de la cámara: A la altura de los ojos del paciente.

- Distancia: A 0,5 metros del paciente.

- Zoom: El necesario para que las cejas llenen la anchura de la foto en la vista frontal.

- Límites de encuadre: Desde cejas hasta labio superior. Incluir totalmente la nariz y las cejas. En la vista lateral, usar mismo zoom y distancia que en el resto.

- Punto de enfoque: Pestañas del ojo más cercano.

- Velocidad: Por lo menos 1/125. Si es menor, deberemos usar trípode.

- Apertura: La suficiente para alcanzar velocidades de 1/125 o ligeramente superiores. Si no se alcanza $1 / 125$, necesitaremos trípode.

- Puntos de referencia: La línea 1 pasa por las cejas en todas ellas.

- Frontal - Línea media sagital coincide con la de la cámara.

- Oblicuas - Punto AH en la pupila más cercana en la vista de $3 / 4$ derecha y $\mathrm{BH}$ en la izquierda.

- Lateral - X sobre canto externo.

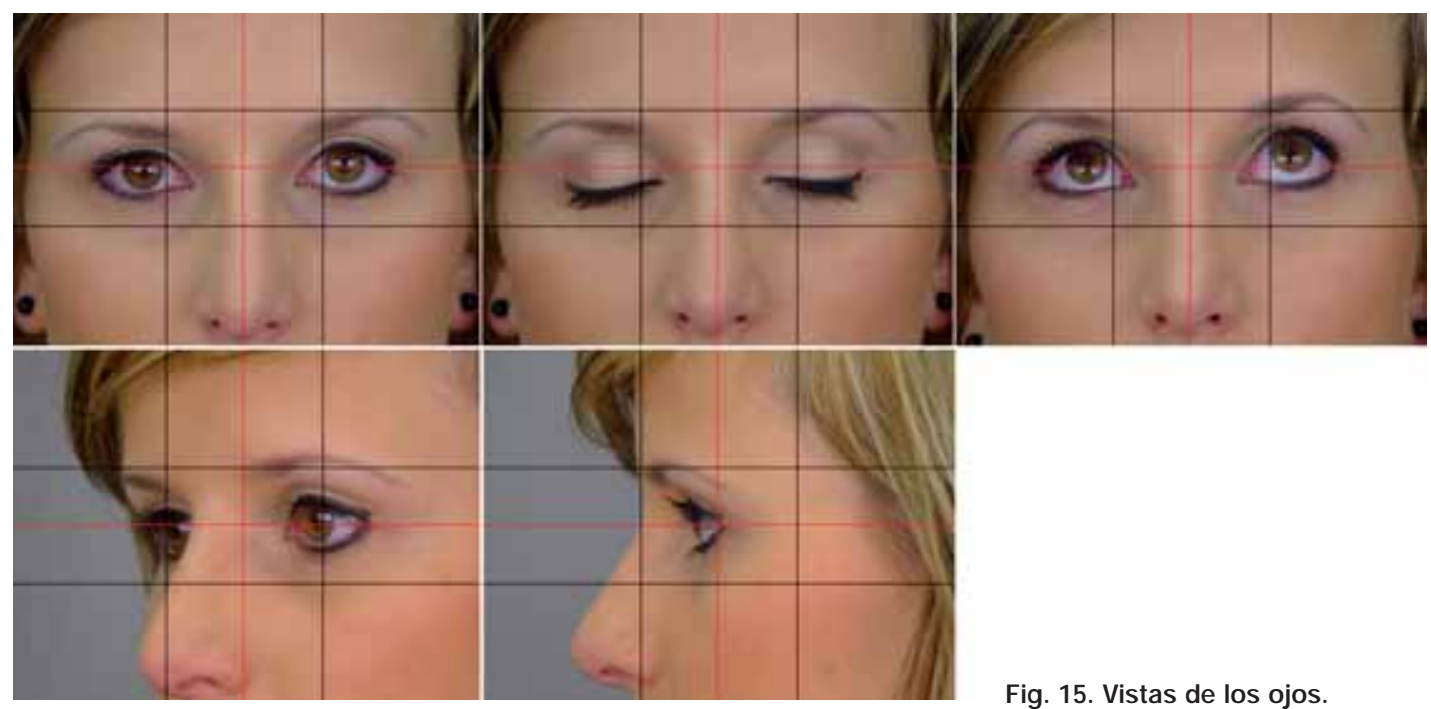

Fig. 15. Vistas de los ojos. 

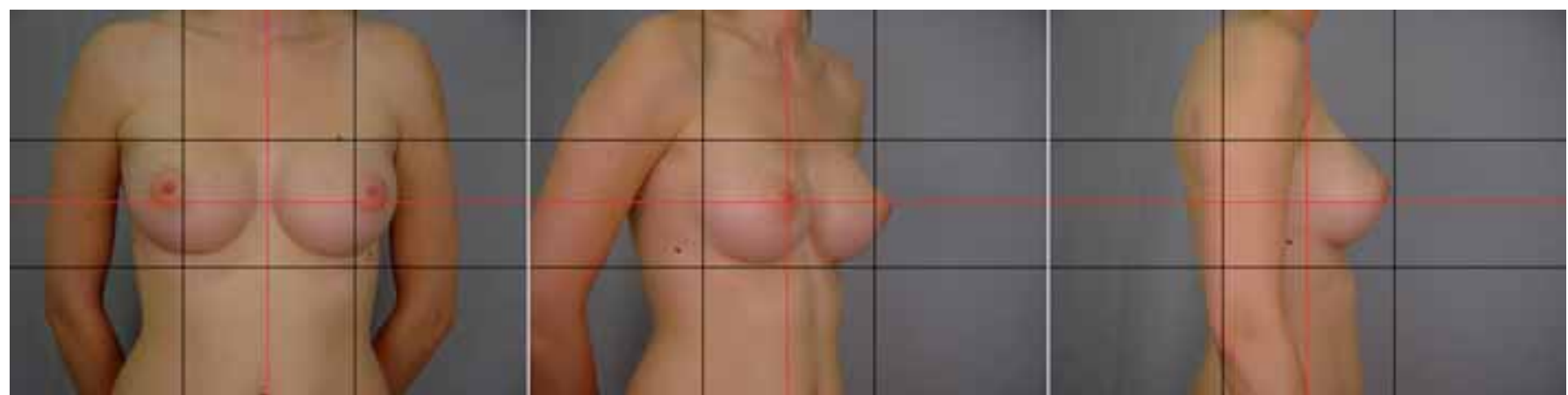

Fig. 16. Vistas de las mamas.

d) Mamas (Fig. 16)

- Posiciones del paciente: Bipedestación, en posición anatómica, con vistas frontal, 3/4 derecha, lateral derecha, 3/4 izquierda y lateral izquierda. En las oblicuas se hará retroversión del brazo más lejano, hasta quedar oculto por el tronco.

- Orientación de la cámara: Horizontal.

- Altura de la cámara: Axila.

- Distancia: 1 metro.

- Zoom: El necesario para que el encuadre sea el siguiente:

- Límites de encuadre: Desde hombros hasta ombligo (todo ello incluido).

- Punto de enfoque: Pezón más próximo.

- Velocidad: Por lo menos 1/125. Si es menor, deberemos usar trípode.

- Apertura: La suficiente para alcanzar velocidades de 1/125 o ligeramente superiores.

- Puntos de referencia

- Frontal y oblicuas - Línea V pasando por yugulum esternal.

- Lateral - Línea V sobre los pliegues axilares anterores. e) Abdomen (Fig. 17)

- Posiciones del paciente: Bipedestación, en posición anatómica, con vistas frontal, 3/4, laterales, laterales con flexión abdominal y sentado. Excepto la frontal y sedestación, todas ellas bilaterales.

- Posición de la cámara: Horizontal.

- Altura de la cámara: Xifoides del paciente

- Distancia: A 1 metro del paciente.

- Zoom: El necesario para que el encuadre sea el siguiente:

- Límites de encuadre: Desde pubis hasta surcos submamarios.

- Punto de enfoque: Ombligo.

- Velocidad: Por lo menos 1/125. Si es menor, deberemos usar trípode.

- Apertura: La suficiente para alcanzar velocidades de 1/125 o ligeramente superiores.

- Puntos de referencia

- Frontal y sentado - ombligo en el centro de la imagen (punto $\mathrm{X}$ )

- Oblicuas y laterales - ombligo sobre punto AH (3/4 izquierda) o BH (3/4 derecha).
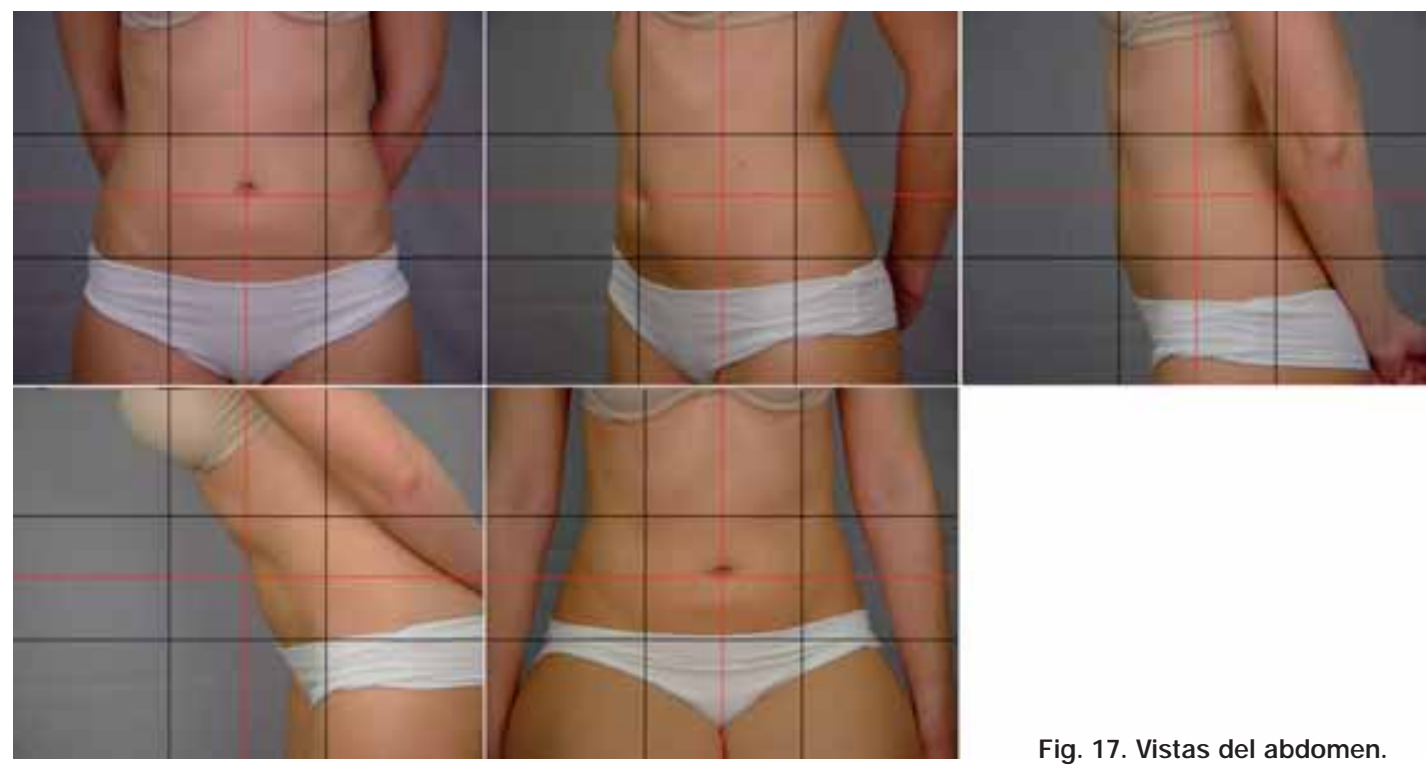

Fig. 17. Vistas del abdomen. 

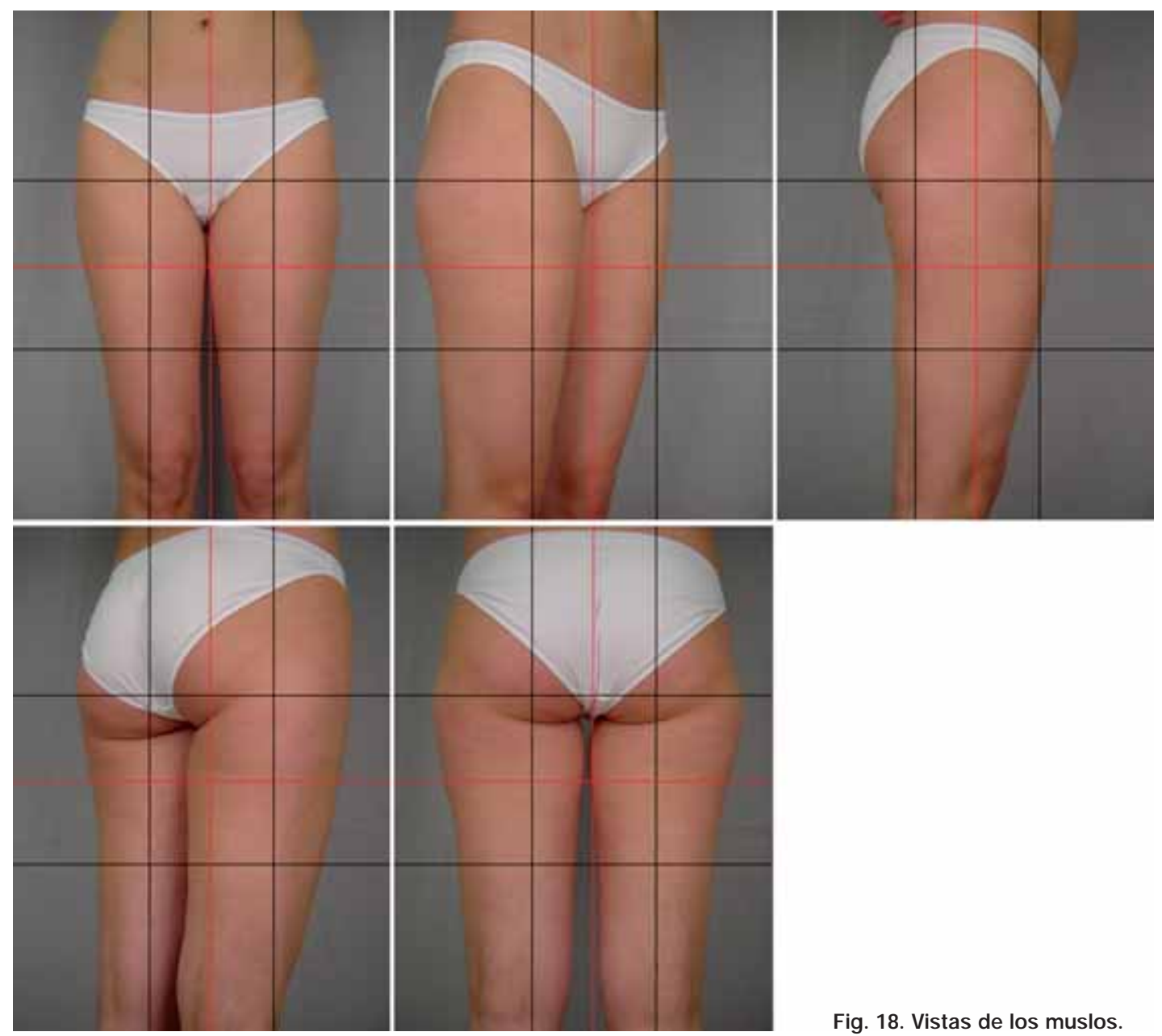

Fig. 18. Vistas de los muslos.

\section{f) Glúteo y muslos (Fig. 18)}

- Posiciones del paciente: Bipedestación, en posición anatómica, pero con los brazos apartados de los muslos, con vistas frontal y girando el paciente su posición en intervalos de $45^{\circ}$ hasta completar $360^{\circ}$ (8 imágenes). Pies ligeramente separados para apreciar el contorno de las caras internas de los muslos.

- Posición de la cámara: Vertical.

- Altura de la cámara: Trocánter del paciente.

- Distancia: A 1 metro del paciente.

- Zoom: El necesario para que el encuadre sea el siguiente:

- Límites de encuadre: Desde ombligo hasta rodillas (ambos incluidos).

- Punto de enfoque: Contorno del muslo más próximo.

- Velocidad: Por lo menos 1/125. Si es menor, deberemos usar trípode.

- Apertura: La suficiente para alcanzar velocidades de 1/125 o ligeramente superiores.

- Puntos de referencia: Eje longitudinal del
Discusión

La importancia de la estandarización fotografía en Cirugía Plástica y Estética ha sido resaltada en numerosos artículos (4, 9-11). algunos de ellos hacen especial hincapié en áreas anatómicas precisas, como cara (Meneghini (5)), contorno corporal (Gherardini (12)) mamas (13), rinoplastia (Galdino (14); otros artículos son más genéricos $(4,5,8,15-18)$, pero todos coinciden en opinar que es necesaria una reproducibilidad de los resultados que sólo se podrá alcanzar si la fotografía se realiza en unas condiciones estándar (siempre iguales). Para esto se propone controlar diversos parámetros fotográficos (distancia, ángulo, iluminación, etc.) De este modo se consigue tener un archivo fotográfico válido, consistente y reproducible.

Con nuestro artículo pretendemos mostrar unas pautas para la estandarización fotográfica y transmitir las que, en nuestra experiencia, resultan útiles. No obstante, cualquier pauta es correcta siempre y cuando sea reproducible. De este modo el archivo fotográfico será consistente y válido.

Para identificar fácilmente a los pacientes fotografiados y evitar dudas y confusiones, proponemos también 
algunas recomendaciones. En nuestra opinión, no se debe pintar el número de historia sobre la piel del paciente, sino renombrar el archivo de imagen al pasarlo al ordenador. Recomendamos usar el siguiente formato para el nombre del archivo: aaaaaaaa.x.\#\#\#.jpg, donde aaaaaaa es el número de historia, $\mathrm{x}$ una letra indicativa de la sesión fotográfica ("a" para la primera sesión, "b" para la segunda, etc) y \#\#\# es un número correlativo de tres cifras para distinguir las fotos dentro de una misma sesión; jpg es la extensión del archivo fotográfico empleado. Existen en el mercado programas informáticos para la gestión de consultas de cirujanos plásticos que renombran los archivos siguiendo este patrón.

Para poder identificar a los pacientes hasta volcar las fotografías al ordenador, es útil realizar una fotografía de la etiqueta de la historia clínica al final de la serie de fotos.

La fecha no necesita ser estampada en la imagen, puesto que al tratarse de fotos digitales, ésta queda almacenada dentro del archivo junto con otra información técnica, en lo que se denomina especificación EXIF (Exchangeable Image File Format). La mayoría de las cámaras digitales realizan esta función.

En cuanto a los intervalos para la realización de fotografías, como norma general, recomendamos sesiones fotográficas antes de la cirugía, tras el marcaje prequirúrgico, al mes de la intervención y a los 3 , 6 y 12 meses de postoperatorio. Las complicaciones también deben ser fotografiadas, aunque nos pueda resultar desagradable. La experiencia enseña que nos pueden ser útiles en muchas ocasiones.

Si el paciente usa algún tipo de prenda de presoterapia o parches anticicatrices, conviene recomendarle que no los use el día que tengamos pensado citarle para la sesión fotográfica, de este modo evitaremos marcas visibles sobre la piel.

Quisiéramos destacar también la importancia de inculcar a nuestros médicos residentes estos conocimientos y exigir la máxima pulcritud en la toma de fotografías y en la selección de las mismas para sus presentaciones y artículos ya desde sus primeros años de formación.

Respecto a la aceptación de fotografías clínicas como medio de prueba admitida en Derecho, depende de la legislación vigente en cada país, por lo que habrá de tenerse en cuenta la misma para determinar su validez y los requisitos exigidos. En España, el artículo 299 de la Ley de Enjuiciamiento Civil admite la imagen como medio de prueba, la cual en cambio, puede ser rechazada si se cuestiona su autenticidad o posible manipulación, por lo que es recomendable adoptar los cuidados precisos que garanticen su autenticidad.

Como consejo general, debemos reiterar que es importante establecer los parámetros que consideramos oportunos según nuestras posibilidades y que estos sean repetidos siempre para poder obtener imágenes comparables.

\section{Conclusiones}

El archivo fotográfico es uno de los bienes más preciados de cualquier cirujano plástico. Pequeñas variaciones (iluminación, vestimenta, ángulo) pueden provocar cambios notables y pueden disminuir notablemente el valor de la fotografía clínica. Por ello, debe dedicarse el tiempo que haga falta a la toma de fotografías, cuidando aspectos tan delicados como los expuestos en este artículo.

A menudo apreciamos en congresos, cómo brillantes ponencias pierden valor cuando se presentan imágenes que no son comparables entre sí debido a una descuidada técnica fotográfica. Algunos autores se disculpan por ello y otros tratan de pasarlas tan rápidamente como sea posible, pero lo cierto es que la mayoría de esas imágenes jamás podrán hacerse de nuevo. Se ha perdido una oportunidad de oro para hacer una buena fotografía. Por ello, para conseguir un registro fotográfico adecuado bien para fines docentes, legales, para comunicarnos mejor con el paciente, informar a compañías de seguros, compartir información con otros colegas, evaluar resultados o cualquier otro uso que vayamos a dar a nuestras fotografías, es de crucial importancia cuidar la técnica fotográfica y construir foto a foto un archivo fotográfico consistente y válido.

Nuestra especialidad se distingue de otras, en cursos y congresos, por la calidad de sus presentaciones y muchas veces es mejor o peor valorado un ponente por la calidad de sus imágenes.

\section{Dirección del autor}

\section{Dr. Francisco Solesio Pilarte}

Sección de Cirugía Plástica Hospital General Universitario de Alicante.

Pintor Baeza 12.03010 Alicante. España.

e-mail: solesio_fra@gva.es

\section{Bibiografía}

1. Rogers BO.: "The first pre- and postoperative photographs of plastic and reconstructive surgery: contributions of Gurdon Buck (1807-1877)". Aesth. Plast Surg 1991;15:19.

2. Wallace AF.: "The early history of clinical photography for burns, plastic and reconstructive surgery". Br J Plast Surg 1985;38:451.

3. Guy C, Guy RJ, Zook EG.: "Discussion. Standards of photography". Plast Reconstr Surg 1984;74:145.

4. DiBernardo BE, Adams RL, Krause J, Fiorillo MA, Gheradini G.: "Photographic standards in plastic surgery". Plast Reconstr Surg 1998; 102:559.

5. Meneghini F.: "Clinical Facial Photography in a Small Office: Lighting Equipment and Technique". Aesth. Plast. Surg. 2001; 25:299. 
6. Schosser RH, Kendrick JP.: "Dermatologic photography". Dermatol Clin 1987;5:445

7. Zarem H.: "Standards of photography". Plast Reconstr Surg 1984;74:137.

8. Yavuzer R., Smirnes S, Jackson IT.: "Guidelines for Standard Photography in Plastic Surgery". Annals of Plastic Surgery 2001;46(3):293.

9. Ellenbogen R, Jankauskas S, Collini FJ.: "Achieving standardized photographs in Aesthetic Surgery". Plast Reconstr Surg 1990; 86:955.

10. Meredith G.: "Facial photography for the orthodontic office". Am J Orthod Dentofac Orthop 1997; 111:463.

11. Nelson GD, Krause JL (ed): "Clinical Photography in Plastic Surgery". Little, Brown and Company. Boston, 1988

12. Gherardini G, Matarasso A, Serure AS, et al.: "Standardization in photography for body contour surgery and suction assisted lipectomy". Plast Reconstr Surg 1997;100:227.
13. IMI National Guidelines: "Breast photography". Journal of visual Communication in Medicine, 2007; 30 (2), Pp. 86-89.

14. Galdino GM, DaSilva and D, Gunter JP.: "Digital photography for rhinoplasty." Plast Reconstr Surg. 2002;1;109(4):1421.

15. Gheradini G.: "Photographic standards in Plastic Surgery". Plast Reconstr Surg 1998;102:559.

16. Blanco Dávila A., Ulloa-Gregori O., Montemayor MC.: "La fotografía y el cirujano plástico". Cir.plást.iberolatinoam. 1993; 19 (2): 189

17. Fittipaldi L.: "Rectaflex. La reflex "mágica" también para las tomas en Cirugía Plástica (segunda parte)". Cir.plást.iberolatinoam. 1994; 20 (4): 401

18. Jemec BIE, Jemec GBE.: "Photographic surgery: standards in clinical photography". Aesthetic Plast Surg 1986;10:177. 